\section{Integration of mental health care into primary care}

\author{
Demonstration cost-outcome study in India and Pakistan
}

D. CHISHOLM, K. SEK AR, K. KISHORE KUMAR, K. SAEED, S. JAMES, M. MUBBASHAR and R. SRINIVASA MURTHY

\begin{abstract}
Background Targeting resources on cost-effective care strategies is important for the global mental health burden.
\end{abstract}

\begin{abstract}
Aims To demonstrate cost-outcome methods in the evaluation of mental health care programmes in low-income countries.

Method Four rural populations were screened for psychiatric morbidity. Individuals with a diagnosed common mental disorder were invited to seek treatment, and assessed prospectively on symptoms, disability, quality of life and resource use.
\end{abstract}

Results Between $12 \%$ and $39 \%$ of the four screened populations had a diagnosable common mental disorder. In three of the four localities there were improvements over time in symptoms, disability and quality of life, while total economic costs were reduced.

Conclusion Economic analysis of mental health care in low-income countries is feasible and practicable. Our assessment of the cost-effectiveness of integrating mental health into primary care was confounded by the naturalistic study design and the low proportion of subjects using government primary health care services.

Declaration of interest The study was funded by the Department for International Development, UK (HPACORD Small Project Grant RD 463).
Recent epidemiological research has demonstrated the very considerable and previously underestimated burden that mental disorders impose on individuals, communities and health services globally (Ustün \& Sartorius, 1995; Murray \& Lopez, 1996). Studies carried out in India and $\mathrm{Pa}$ kistan have likewise shown the high prevalence and disabling consequences of psychiatric disorder (Mumford et al, 1997; Patel et al, 1998). Alongside efforts to raise political will and public awareness (Jenkins, 1997), there is a need to invest resources into cost-effective care and prevention strategies. Integration of mental health care into the existing primary health care system has been widely advocated, but along with other strategies, it has not been subjected to economic evaluation, even though such evidence is needed to stimulate investment (Gulbinat et al, 1996; Shah \& Jenkins, 1999). This paper describes a demonstration project which set out to apply cost-outcome methods in the context of mental health care programmes in lowincome countries.

\section{METHOD}

\section{Selection of collaborating sites}

The demonstration project was carried out as part of the evaluative research programmes of the Institute of Psychiatry, Rawalpindi (Pakistan) and the National Institute of Mental Health and Neurosciences, Bangalore (India). Selection of the two collaborating study sites was based on existing networks, a proven ability to carry out required research activities and the active pursuit of a community mental health care strategy.

\section{Study design}

The chosen design of the study was to recruit and follow up patients meeting ICD-10 diagnostic criteria for affective and neurotic disorders (World Health
Organization, 1992a) from two rural catchment areas, one reflecting the standard primary health care system, and one in which mental health care had been incorporated into primary health care practice. The standard primary care centres were Jigani (Bangalore) and Lehtrar (Rawalpindi), and the centres in which mental health training and support had been given were Sakalwara (Bangalore) and Taxila (Rawalpindi). Following previous studies and methods (Mumford et al, 1997), a community survey design was adopted, involving the mapping of whole local communities and randomly selecting members of individual households. This approach enabled the health-seeking behaviour of the whole local population (rather than primary care attenders only) to be observed, thereby affording an opportunity of assessing the extent of unmet mental health need.

\section{Recruitment of study participants}

A two-stage process was used to recruit subjects: a) initial screening for mental disorder by trained research field-workers via the Self Report Questionnaire (SRQ) (Harding et al, 1980); b) for all those scoring above the SRQ threshold for caseness (in India, a score of 5 or more indicates a probability of psychiatric morbidity; in $\mathrm{Pa}$ kistan, 6 or more), a diagnostic assessment was made by a psychiatrist (the Pakistan Assessment Schedule: Mumford et al, 1997; in India, the Schedule for Clinical Assessment in Neuropsychiatry: World Health Organization, 1992b). Both instruments provide ICD-10 diagnoses. Only new episodes of affective and neurotic disorder were included (ICD-10 categories F32-48), defined as the presence of a set of symptoms for which no mental health treatment had been sought in the past month. Other inclusion criteria included the age of patients (18-60 years) and local residence.

\section{Description of study intervention}

Subjects meeting diagnostic criteria were informed of their health status by the psychiatrist and were provided with information about possible treatment options, how and where to seek local treatment for their condition, and advice about psychological problems, such as alcohol or drug dependency in the spouse. 


\section{Tests administered to subjects}

A range of clinical/social instruments were administered via face-to-face interviews at entry into the study and again 3 months later, in order to observe any changes in outcomes. Data were obtained on symptoms (Hamilton Depression Rating Scale) (Hamilton, 1960), disability (Brief Disability Questionnaire) (Von Korff et al, 1996) and quality of life (WHOQOL Brev) (World Health Organization, 1998). Further data were collected from subjects via the completion of a socio-demographic form (age, gender, education, employment, income) and a service utilisation form (contact in the previous 3 months with primary health care providers, traditional healers and hospital services; medication use; support and help from family and friends), based on the Client Sociodemographic and Service Receipt Inventory (Chisholm et al, 2000) and adapted for the purpose and context of the present study.

\section{Cost measures}

The economic analysis was from the viewpoint of society: not only were the costs of the health sector considered, but also the time costs and out-of-pocket expenses of users and their (informal) carers. Unit costs were derived for a range of primary health care contacts (keyworkers, such as a doctor, nurse or pharmacist; other workers, such as female health visitors; and psychiatrist), on the basis of facility-specific data on staffing levels and salaries, plus other revenue and capital costs relating to the premises at which the professionals worked. Total annual costs of professionals were divided by working days per year and hours worked per day, and the resulting values were subsequently weighted by the ratio of time spent in contact with patients to time spent not in contact with patients. A series of other unit costs was also estimated for out-patient and in-patient hospital contacts, based on available hospital finance data.

Privately purchased health care and medications were costed as the fees that patients or their families actually paid to local providers (recorded in the service receipt schedule). Where patients or families contributed to the cost of publicly provided hospital care, this was separately quantified and subtracted from the total cost that would have applied if fully financed by government. Finally, estimates were calculated for the opportunity costs associated with informal care-giving (hours per week multiplied by the hourly wage rate for a house-servant or maid: Indian $\mathrm{Ru}-$ pees 6; Pakistani Rupees 12), and also for time spent travelling to, or waiting for, care providers, and lost opportunities for work (derived from the patient's estimated wage, based on gender-adjusted average earnings for labourers or skilled workers).

\section{Analysis}

The purpose, design and scale of this demonstration project precluded the conduct of a full-scale cost consequences analysis (which would require a controlled experimental study design, a larger sample size and a longer follow-up period). Moreover, the observational design of the study, together with differences in the structure of local health services, means that relative changes in costs and outcomes between catchment areas are not necessarily causally related, so that it would not be safe to draw inferences based on such comparisons (adjustment for differences in characteristics of subjects and sites, using treatment-effect regression coefficients, would not alter this fact). Accordingly, the focus of analysis was not on comparisons between catchment areas or sites, but on changes over time in the principal cost and outcome domains for each of the localities (using a two-sided paired-sample $t$-test statistic).

\section{RESULTS}

\section{Description of study sites}

The villages of Jigani and Sakalwara lie 12$20 \mathrm{~km}$ from the city of Bangalore. Sakalwara is a small agriculture-based village about $2 \mathrm{~km}$ from the main road, and Jigani is a larger village on the main road with a higher proportion of inhabitants engaged in skilled factory work. In the Rawalpindi site, Lehtrar is a remote rural community some 90 minutes' drive away from Rawalpindi, while Taxila is located in a more suburban setting where there is heavy plant production nearby.

\section{Psychiatric epidemiology of catchment areas}

A total of 795 adults was screened with the SRQ in the two catchment areas of the Bangalore site. The prevalence of diagnosable common mental disorder using samples from these localities was $18.9 \%$ in Sakalwara and $12.5 \%$ in Jigani. In the Rawalpindi site, 948 SRQs were administered, and the proportion of confirmed cases as a percentage of the screened population was $28 \%$ in Lehtrar and 39\% in Taxila. Comparison of the mean SRQ scores for the cases selected for full psychiatric assessment in the two sites revealed a statistically significant difference, with subjects in Rawalpindi (mean $=11.17$, s.d. 3.48 ) scoring on average 1.33 points higher than subjects in Bangalore (mean $=9.84$, s.d. 3.96).

The various (primary) diagnoses reached for the populations sampled are given in Table 1. Most cases $(72 \%$ in Bangalore, $92 \%$ in Rawalpindi) fall under the broad diagnostic category of mood (affective) disorders (ICD-10 codes F32-39), the remainder being made up of neurotic and somatisation disorders. The most common (primary) diagnoses in the Bangalore site were dysthymia ( $68 \%$ of the sample), and phobic and other anxiety disorders (19\%). In contrast, only $8 \%$ of cases in Rawalpindi were diagnosed as having phobic and other anxiety disorders, and there were no diagnosed cases of dysthymia. Rather, the majority of cases were diagnosed as having depressive episodes $(22 \%$ mild, $32 \%$ moderate and $35 \%$ severe, of which over a third had psychotic symptoms).

\section{Socio-demographic characteristics of the populations sampled}

The socio-demographic characteristics of the populations sampled in each of the four catchment areas of the study are given in Table 2. There are a number of broad similarities between the catchment areas, including the preponderance of women (71$87 \%$ of the samples), the proportion of married people $(62-80 \%)$, and the small minority who are currently employed (2$13 \%)$. There are also clear differences between and within sites, however; such as the age distribution (for example, $50 \%$ of subjects in Lehtrar were aged 45 years or more, compared with only $13 \%$ in Taxila), the range of monthly incomes and the extent of educational achievement (although much of the information was missing for the Rawalpindi area).

\section{Rates of contact with services}

Rates of contact with primary care, hospital care and private services are reported in Table 3. In the standard model locality in India (Jigani), $17 \%$ of the population had contact with a government primary care provider at baseline, $33 \%$ had contact with a private community-based provider, $10 \%$ 
Table I Diagnosis

\begin{tabular}{|c|c|c|c|c|c|}
\hline \multirow[t]{2}{*}{ Diagnosis (ICD-I0) } & \multirow{2}{*}{$\begin{array}{l}\text { ICD-10 } \\
\text { code }\end{array}$} & \multicolumn{2}{|c|}{ Bangalore } & \multicolumn{2}{|c|}{ Rawalpindi } \\
\hline & & $n$ & $\%$ & $n$ & $\%$ \\
\hline Mild depressive episode & F32.0 & 3 & 2.5 & 29 & 21.8 \\
\hline Moderate depressive episode & F32.I & 1 & 0.8 & 42 & 31.6 \\
\hline Severe depressive episode (with no psychotic symptoms) & $\mathrm{F} 32.2$ & 0 & 0 & 32 & 24.1 \\
\hline Severe depressive episode (with psychotic symptoms) & F32.3 & 0 & 0 & 19 & 14.3 \\
\hline Dysthymia & F34.I & 82 & 68.3 & 0 & 0 \\
\hline Phobic and other anxiety disorders & $\mathrm{F} 40, \mathrm{~F} 4 \mathrm{I}$ & 23 & 19.2 & II & 8.3 \\
\hline $\begin{array}{l}\text { Other diagnosis (adjustment and somatoform disorders, } \\
\text { neurasthenia) }\end{array}$ & $\begin{array}{l}\mathrm{F} 43, \mathrm{~F} 45 \text { \& } \\
\mathrm{F} 48\end{array}$ & II & 9.2 & 0 & 0 \\
\hline
\end{tabular}

had attended as out-patients and 5\% had been in-patients during the previous month. Rates of service uptake in the integrated care locality of Sakalwara were $37 \%$ for a government primary health care (PHC)

worker, $25 \%$ for private community-based practitioners, $7 \%$ for out-patient services and 3\% for in-patient services. These rates do not alter appreciably over the followup period.
Rates of contact were generally higher in the Rawalpindi site. For example, the proportion seeking care from a government PHC provider in the non-intervention locality (Lehtrar) is $67 \%$ at baseline, considerably higher than the rate observed in Taxila (27\%). Over the follow-up period, PHC rates of contact increased to $88 \%$ in Lehtrar and $52 \%$ in Taxila, a positive trend. Rates of contact with out-patient services are higher for the Taxila locality, which is in part because the access to such care is relatively easier here than in Lehtrar.

\section{Health care costs}

While there were considerable variations in cost between sampled individuals within particular localities, a number of general trends emerge from the cost analysis (Table 4). The mean cost of contacts with government PHC workers, which would

Table 2 Baseline socio-demographic characteristics

\begin{tabular}{|c|c|c|c|c|c|c|c|c|}
\hline \multirow[t]{3}{*}{ Socio-demographic variable } & \multicolumn{4}{|c|}{ Bangalore, India } & \multicolumn{4}{|c|}{ Rawalpindi, Pakistan } \\
\hline & \multicolumn{2}{|c|}{ Standard care (Jigani) } & \multicolumn{2}{|c|}{ Integrated care (Sakalawara) } & \multicolumn{2}{|c|}{ Standard care (Lehtrar) } & \multicolumn{2}{|c|}{ Integrated care (Taxila) } \\
\hline & $n$ & $\%$ & $n$ & $\%$ & $n$ & $\%$ & $n$ & $\%$ \\
\hline \multicolumn{9}{|l|}{ Gender } \\
\hline Male & 13 & 21.7 & 16 & 26.7 & 20 & 28.6 & 8 & 12.7 \\
\hline Female & 47 & 78.3 & 44 & 73.3 & 50 & 71.4 & 55 & 87.3 \\
\hline \multicolumn{9}{|l|}{ Age (years) } \\
\hline $16-30$ & 28 & 46.7 & 17 & 28.3 & 15 & 21.4 & 26 & 41.3 \\
\hline $31-45$ & 19 & 31.7 & 20 & 33.3 & 19 & 27.1 & 29 & 46.0 \\
\hline $45-60$ & 13 & 21.7 & 23 & 38.3 & 36 & 51.4 & 8 & 12.7 \\
\hline \multicolumn{9}{|l|}{ Marital status } \\
\hline Single & 7 & 11.7 & 3 & 5.0 & 9 & 12.9 & 17 & 27.0 \\
\hline No longer married & 10 & 18.3 & 9 & 15.0 & 12 & I7.I & 7 & II.I \\
\hline \multicolumn{9}{|l|}{ Children } \\
\hline None/not applicable & 13 & 21.7 & 9 & 15.0 & 14 & 20.0 & 21 & 33.3 \\
\hline $\mathrm{I}-3$ & 29 & 48.3 & 26 & 43.3 & 18 & 25.7 & 10 & 15.9 \\
\hline$\geqslant 4$ & 18 & 30.0 & 25 & 41.7 & 38 & 54.3 & 32 & 50.8 \\
\hline \multicolumn{9}{|l|}{ Employment } \\
\hline Employed & 6 & 10.0 & 8 & 13.3 & 8 & II.4 & I & 1.6 \\
\hline Not employed & 21 & 36.0 & 26 & 43.3 & 13 & 18.6 & 20 & 31.7 \\
\hline Housewife & 33 & 54.0 & 26 & 43.3 & 49 & 70.0 & 42 & 66.7 \\
\hline \multicolumn{9}{|l|}{ Income' (monthly) } \\
\hline$<$ R 2000 & 41 & 68.3 & 51 & 85.0 & 50 & 71.4 & 19 & 30.2 \\
\hline R 2000-5000 & 19 & 31.7 & 8 & 13.3 & 17 & 24.3 & 36 & 57.1 \\
\hline$>$ R 5000 & 0 & 0 & I & 1.7 & 3 & 4.3 & 8 & 12.7 \\
\hline Primary school & II & 18.3 & 4 & 6.7 & 8 & II.4 & 12 & 19.0 \\
\hline Secondary school & 15 & 25.0 & 6 & 10.0 & 15 & 21.4 & 18 & 28.6 \\
\hline Unknown/missing & 0 & 0 & 0 & 0 & 26 & 37.1 & 20 & 31.7 \\
\hline
\end{tabular}

I. Expressed as gross personal income in local currencies (not adjusted). 
Table 3 Rates of contact with primary and secondary health care services

\begin{tabular}{|c|c|c|c|c|c|c|c|c|}
\hline \multirow[t]{3}{*}{ Service contact (\%) } & \multicolumn{4}{|c|}{ Bangalore, India } & \multicolumn{4}{|c|}{ Rawalpindi, Pakistan } \\
\hline & \multicolumn{2}{|c|}{ Jigani $(n=60)$} & \multicolumn{2}{|c|}{ Sakalwara $(n=60)$} & \multicolumn{2}{|c|}{ Lehtrar $(n=67)$} & \multicolumn{2}{|c|}{ Taxila $(n=63)$} \\
\hline & Baseline & Follow-up & Baseline & Follow-up & Baseline & Follow-up & Baseline & Follow-up \\
\hline Government PHC worker (doctor, nurse, health worker) & 17 & 25 & 37 & 43 & 67 & 88 & 27 & 52 \\
\hline Private community (traditional or faith healer) & 33 & 27 & 25 & 25 & 61 & 66 & 60 & 82 \\
\hline Hospital out-patient (psychiatric and general) & 10 & 18 & 7 & 5 & 27 & 22 & 33 & 56 \\
\hline Hospital in-patient (psychiatric and general) & 5 & 0 & 3 & 5 & 7 & 18 & 2 & 5 \\
\hline
\end{tabular}

PHC, primary health care.

be expected to rise if individuals seek appropriate treatment for their diagnosed mental health condition, does in fact increase in the localities where mental health care training and support has been introduced (Sakalwara and Taxila), whereas there is very little change in the standard care localities. By contrast, the costs of contacts with community-based private health care providers (general practitioners, traditional healers) dropped in all localities, significantly so except in the

Table 4 Costs of health care to patients and family at baseline and follow-up

\begin{tabular}{|c|c|c|c|c|c|c|c|c|c|c|c|c|}
\hline \multirow{3}{*}{$\begin{array}{l}\text { (a) Bangalore site } \\
\text { (Indian Rupees per month, 1998)' }\end{array}$} & \multicolumn{6}{|c|}{ Standard model - Jigani $(n=60)$} & \multicolumn{6}{|c|}{ Integrated model - Sakalawara $(n=60)$} \\
\hline & \multicolumn{2}{|c|}{ Baseline } & \multicolumn{2}{|c|}{ Follow-up } & \multirow[b]{2}{*}{ Change } & \multirow[b]{2}{*}{$(95 \% \mathrm{Cl})$} & \multicolumn{2}{|c|}{ Baseline } & \multicolumn{2}{|c|}{ Follow-up } & \multirow[b]{2}{*}{ Change } & \multirow[b]{2}{*}{$(95 \% \mathrm{Cl})$} \\
\hline & Mean & (s.d.) & Mean & (s.d.) & & & Mean & (s.d.) & Mean & (s.d.) & & \\
\hline \multicolumn{13}{|l|}{ Health care costs } \\
\hline - Primary health care (government) & 10 & (31) & 9 & (23) & -1 & $(-8$ to II $)$ & 19 & (38) & 42 & (154) & 23 & (18 to 63) \\
\hline - Primary/community care (private) & 103 & (249) & 12 & (30) & -91 & $(-155 \text { to }-27)^{*}$ & 77 & $(418)$ & 67 & (488) & -10 & $(-153$ to 173$)$ \\
\hline - Hospital care (government) & 5 & (36) & 39 & $(122)$ & 35 & $(\text { I to } 68)^{*}$ & 8 & $(42)$ & 127 & (930) & 119 & $(-122$ to 360$)$ \\
\hline - Hospital care (private) & 61 & (243) & 15 & (59) & -46 & $(-111$ to 19$)$ & 22 & (99) & 50 & (276) & 28 & $(-4 \mid$ to 98$)$ \\
\hline - Medicines (privately paid) & 55 & (II5) & 28 & (61) & -27 & $(-61$ to 6$)$ & 33 & $(87)$ & 41 & (196) & 8 & $(-37$ to 53$)$ \\
\hline Sub-total & 234 & $(454)$ & 103 & (148) & $-|3|$ & $(-260 \text { to }-2)^{*}$ & 159 & $(516)$ & 328 & $(1192)$ & 169 & ( -149 to 487$)$ \\
\hline \multicolumn{13}{|l|}{ Patient and family costs } \\
\hline - Informal care-giving & 144 & $(232)$ & 78 & (199) & -67 & $(-145$ to 12$)$ & 148 & (259) & 65 & $(122)$ & -83 & $(-155 \text { to }-10)^{*}$ \\
\hline - Travel and time costs & 73 & (298) & 4 & (15) & -69 & $(-146$ to 8$)$ & 31 & $(85)$ & II & $(47)$ & -20 & $(-42$ to 3$)$ \\
\hline - Lost work opportunities & 260 & (554) & 53 & (17I) & -207 & $(-327 \text { to }-86)^{* *}$ & 363 & (590) & 44 & $(122)$ & -319 & $(-476 \text { to }-162)^{* *}$ \\
\hline Total costs & 711 & (984) & 237 & (360) & -474 & $(-730 \text { to }-217)^{* *}$ & 701 & (791) & 448 & (1292) & -253 & ( -604 to 97$)$ \\
\hline
\end{tabular}

(b) Rawalpindi site

(Pakistani Rupees per month, 1998)'
Integrated model - Taxila $(n=63)$

Baseline
Mean (s.d.)

Health care costs

- Primary health care (government)

- Primary/community care (private)

- Hospital care (government)

- Hospital care (private)

- Medicines (privately paid)

Standard model - Lehtrar $(n=67)$
$\frac{\text { Baseline }}{\text { Mean (s.d.) }} \frac{\text { Follow-up }}{\text { Mean (s.d.) Change } \quad(95 \% \mathrm{Cl})}$

$\begin{array}{rrrrrl}90 & (133) & 81 & (62) & -10 & (-34 \text { to } 15) \\ 108 & (164) & 47 & (69) & -61 & (-102 \text { to }-20)^{*} \\ 180 & (454) & 299 & (691) & 119 & (-76 \text { to } 314) \\ 41 & (136) & 49 & (134) & 8 & (-22 \text { to } 38) \\ 137 & (164) & 119 & (99) & -18 & (-58 \text { to } 23)\end{array}$

$10 \quad(24) \quad 23$

$134 \quad(218) \quad 80$

(36) 13

(2 to 23$)^{*}$

$\begin{array}{rr}(121) & -54 \\ \text { (376) } & 156\end{array}$

$(-106 \text { to }-2)^{*}$

$\begin{array}{lllll}53 & \text { (155) } & 289 & (858) & 236\end{array}$

(62 to 249)**

$\begin{array}{rrrrrrl} & 137 & (164) & 119 & (99) & -18 & (-58 \text { to } 23) \\ \text { Sub-total } & 562 & (784) & 610 & (799) & 48 & (-194 \text { to 291) }\end{array}$

$\begin{array}{lllll}392 & (1201) & 400 & (747) & 7\end{array}$

(16 to 455$)^{*}$

$\begin{array}{lllll}650 & (1303) & 1020 & (1557) \quad 370\end{array}$

( -338 to 353$)$

( -134 to 874$)$

Patient and family costs

- Informal care-giving

II86 (134I) 1486 (1249) $300 \quad$ (- I0I to 70I) $\quad \begin{array}{llllllll}I 170 & \text { (1060) } & 3026 & \text { (1398) } & 1855 & \text { (1449 to 226I)** }\end{array}$

- Travel and time costs

$581 \quad(1092) \quad 146 \quad(184)-435 \quad(-684 \text { to }-186)^{* *} \quad 130 \quad(197) \quad 145 \quad(210) \quad 15$

$(-52$ to 83$)$

- Lost work opportunities

$\begin{array}{llllllllll}739 & (709) & 250 & (190) & -489 & (-668 \text { to }-315)^{* *} & \text { II5I } & (1149) & 614 & (759)-537\end{array}$

$(-816 \text { to }-258)^{* *}$

Total cost

3084 (2760) 2405 (1615) $-678 \quad$ (-1358 to 2$)$

$\begin{array}{lllll}3107 & (2365) & 4807 & (2540) & 1700\end{array}$

(973 to 2425$)^{* *}$

$* P<0.05$ (2-sided paired $t$-test); **P $<0.01$.

I. For information: Exchange rates at $1 / 1 / 1999: \ell \mathrm{I}=$ Indian Rupees 70; Pakistani Rupees 82. 
Sakalwara locality. Privately incurred expenditures on medication, on the other hand, remained relatively constant over the 3-month period. Aggregated health care costs are increased, but not statistically significantly so, in both integrated care localities, resulting mainly from increased contact with secondary care services.

\section{Total costs to society}

The opportunity costs associated with lost work, time and travel to obtain treatment, and informal care-giving by family members were also estimated (Table 4). The costs of lost working days decreased significantly in all localities, particularly in the Bangalore site, where costs fell by 80 $90 \%$. Opportunity costs associated with informal care-giving (help from relatives in or outside the home, with e.g. child care, cooking and shopping) are less in the Bangalore site also, but considerably more in the Rawalpindi site, notably in Taxila.

When all costs are combined (health care and patient/family costs), the magnitude of the economic impact of depression and anxiety becomes evident: in the Bangalore site, the cost at baseline is Indian Rupees 700 per month, and in the Rawalpindi site the baseline cost is more than Pakistani Rupees 3000 per month. To put this in context, this is equivalent to between 7 and 14 days of an agricultural worker's wages in India, and approximately 20 days in Pakistan. These total costs, however, had fallen appreciably by the follow-up assessment point in all localities except Taxila, where there was a significant increase.

\section{Outcome assessments}

Baseline depression scores were markedly higher in the Rawalpindi site, indicating greater psychiatric morbidity. However, since the interviewers were not trained simultaneously or by the same trainer, it is conceivable that rating methods differed in the two sites. Results are therefore couched in terms of changes in scores over time in the two separate sites (Table 5). In overall terms, there has been an improvement in the positive outcome domain of quality of life, and significant reductions in symptomatology and disability. More specifically, in three of the four localities, there is a substantial reduction in levels of depression symptoms (between 5.1 and 8.6 points lower, each statistically significant at $P<0.01$ ). The exception is Taxila, which showed only a very modest, and not significant, reduction (0.5 points). Results for the Brief Disability Questionnaire (BDQ) closely reflect those for depression scores, in the sense that in all localities except Taxila there is a significant reduction by 6.2 to 7.9 points in overall disability score. There is a slight, though not statistically significant, increase in BDQ score for Taxila (0.3 points higher). There were statistically significant improvements in quality of life scores in Sakalwara and Lehtrar. There were only modest improvements in the Jigani catchment area population, and in Taxila there was no clear change either way.

\section{Summary of changes in scores for key cost and outcome domains}

A summary of observed changes over time in the principal cost and outcome domains is given in Table 6, including a comparison of change scores between those who had been in contact with government primary and secondary health care and those who had only consulted local practitioners or not accessed care at all. For both localities in the Bangalore site, there are higher service costs but greater improvements in depression score (significantly so in Jigani, but not in Sakalwara, the integrated care locality). Government health care users also show greater improvements in disability change scores. There are no statistically significant differences in change scores in the Rawalpindi site, but again service costs are higher among government health care users. Depression and disability change scores are actually better among the (very small number of) non-users in the Lehtrar locality, and in Taxila users of government health care services showed a marginally better mean change score for depression but a slightly worse score for disability. In the two integrated care localities, therefore, there are no clear advantages in clinical or economic outcomes for users of government primary and secondary care services.

\section{DISCUSSION}

\section{Feasibility of economic analysis of mental health care in low-income countries}

Against the backdrop of a widening recognition of the public health burden of mental disorders, this research study set out to develop and test methods for conducting economic analysis of community mental health programmes in low-income countries. Such evaluative techniques, if appropriate and feasible to employ, enable data to be generated on the relative costs and benefits of alternative responses to mental disorder in the community, which can subsequently inform policy discussion and service development. On the basis of this demonstration project, we can conclude that economic analysis in low-income countries is both feasible and practicable. In reaching this conclusion, however, we realise that a number of factors have contributed to the successful conduct of this particular study, including the research and training capacity of the collaborating institutions, the interest shown in incorporating economic perspectives into existing evaluative programmes, and the professionalism of keyworkers. We are nevertheless confident that other centres in low-income countries who possess a grounding in research methodology and an interest in addressing issues of cost-effectiveness will be able to carry out economic analysis alongside their other activities. To this end, a brief set of guidelines has been prepared (available from the corresponding author), which are aimed at providing a set of principles and procedures that need to be followed in order to carry out an economic evaluation of a mental health care intervention in this context.

\section{Economic burden of common mental disorders}

The health care and other opportunity costs incurred by individuals (and their families) in the sample with a diagnosed common mental disorder were considerable. It is important to note that the preponderance of these costs were privately incurred expenditures, and that a significant category of health care cost was consultations with local general or traditional practitioners (neither of whom are trained or qualified to detect or treat psychiatric morbidity). Thus, while individuals (and households) are seeking help, and spending significant amounts of money in the process, they are not in the main receiving appropriate care for their mental health condition. The imputed costs associated with reported levels of informal care-giving, travelling time and expenses, and lost days of work are also very considerable, and in fact exceed formal health care costs by as much as three times (a finding echoed in other studies of the cost of illness, for depression and other affective disorders, carried out in 


\begin{tabular}{|c|c|c|c|c|c|c|c|c|c|c|c|}
\hline \multirow[t]{3}{*}{ (a) Bangalore site } & \multicolumn{5}{|c|}{ Standard model - Jigani $(n=60)$} & \multicolumn{6}{|c|}{ Integrated model - Sakalawara $(n=60)$} \\
\hline & \multicolumn{2}{|c|}{ Baseline } & \multicolumn{2}{|c|}{ Follow-up } & \multirow[b]{2}{*}{$(95 \% \mathrm{Cl})$} & \multicolumn{2}{|c|}{ Baseline } & \multicolumn{2}{|c|}{ Follow-up } & \multirow[b]{2}{*}{ Change } & \multirow[b]{2}{*}{$(95 \% \mathrm{Cl})$} \\
\hline & Mean & (s.d.) & Mean & (s.d.) & & Mean & (s.d.) & Mean & (s.d.) & & \\
\hline HDRS & 11.27 & $(7.00)$ & 4.43 & $(4.30)$ & $-6.83(-4.80 \text { to }-8.86)^{* *}$ & 10.70 & $(5.62)$ & 5.60 & $(4.5 I)$ & -5.10 & $(-3.43 \text { to }-6.77)^{* *}$ \\
\hline BDQ & 7.42 & (3.49) & 3.28 & $(4.18)$ & $-4.13(-2.80 \text { to }-5.47)^{* *}$ & 8.45 & $(4.66)$ & 3.10 & (3.46) & -5.35 & $(-3.99 \text { to }-6.71)^{* *}$ \\
\hline - Days unable to carry out activities & 2.40 & (4.57) & 1.03 & $(3.09)$ & $-1.37(-0.12 \text { to }-2.61)^{*}$ & 3.53 & $(7.40)$ & 0.67 & $(1.96)$ & -2.87 & $(-0.93 \text { to }-4.80)^{* *}$ \\
\hline - Days spent in bed due to illness & 0.65 & $(1.36)$ & 0.47 & $(1.52)$ & $-0.18(-0.69$ to 0.32$)$ & 1.58 & $(5.03)$ & 0.22 & $(0.78)$ & -1.37 & $(-0.04 \text { to }-2.69)^{*}$ \\
\hline \multicolumn{12}{|l|}{ WHOQOL Bref } \\
\hline - Domain I (physical health) & 13.88 & $(2.84)$ & 14.29 & $(2.58)$ & $0.40(-0.4 \mathrm{I}$ to $\mathrm{I} .22)$ & 13.09 & $(3.14)$ & 14.08 & $(2.14)$ & 0.99 & $(0.26 \text { to } 1.72)^{*}$ \\
\hline - Domain 2 (psychological) & 12.91 & $(2.97)$ & 13.75 & $(2.68)$ & 0.85 (0.04 to 1.65$)^{*}$ & 12.69 & $(3.20)$ & 13.86 & $(2.53)$ & 1.17 & $(0.42 \text { to } 1.92)^{* *}$ \\
\hline - Domain 3 (social relationships) & 13.43 & $(3.25)$ & 13.76 & $(2.74)$ & $0.33(-0.62$ to 1.29$)$ & 13.20 & $(3.14)$ & 13.61 & $(2.43)$ & 0.41 & $(-0.37$ to 1.19$)$ \\
\hline - Domain 4 (environment) & 14.32 & $(2.12)$ & 14.36 & $(1.97)$ & $0.04(-0.54$ to 0.62$)$ & 12.33 & $(2.45)$ & 13.47 & $(2.15)$ & 1.13 & $(0.58 \text { to } \mathrm{I} .68)^{* *}$ \\
\hline \multirow[t]{3}{*}{ (b) Rawalpindi site } & \multicolumn{5}{|c|}{ Standard model - Lehtrar $(n=67)$} & \multicolumn{6}{|c|}{ Integrated model - Taxila $(n=63)$} \\
\hline & \multicolumn{2}{|c|}{ Baseline } & \multicolumn{2}{|c|}{ Follow-up } & \multirow[b]{2}{*}{ Change } & \multicolumn{2}{|c|}{ Baseline } & \multicolumn{2}{|c|}{ Follow-up } & \multirow[b]{2}{*}{ Change } & \multirow{2}{*}{$(95 \% \mathrm{Cl})$} \\
\hline & Mean & (s.d.) & Mean & (s.d.) & & Mean & (s.d.) & Mean & (s.d.) & & \\
\hline HDRS & 29.36 & $(4.89)$ & 20.72 & $(5.12)$ & $-8.64(-10.19 \text { to }-7.10)^{* *}$ & 21.89 & $(6.91)$ & 21.38 & $(5.82)$ & -0.51 & $(-1.82$ to 0.80$)$ \\
\hline $\mathrm{BDQ}$ & 16.93 & $(3.91)$ & 12.18 & $(4.47)$ & $-4.75(-6.18 \text { to }-3.31)^{* *}$ & 7.48 & $(3.8 I)$ & 7.78 & $(3.73)$ & 0.30 & $(-0.37$ to 0.98$)$ \\
\hline - Days unable to carry out activities & 5.27 & $(6.23)$ & 4.24 & $(2.76)$ & $-1.03(-2.64$ to 0.58$)$ & 6.44 & (7.53) & 10.84 & (II.04) & 4.40 & $(1.57 \text { to } 7.23)^{* *}$ \\
\hline - Days spent in bed due to illness & 3.12 & $(4.84)$ & 1.84 & $(2.25)$ & $-1.28(-2.58 \text { to } 0.01)^{*}$ & 3.03 & $(5.44)$ & 6.05 & $(8.52)$ & 3.02 & $(0.90 \text { to } 5.14)^{* *}$ \\
\hline \multicolumn{12}{|l|}{ WHOQOL Bref } \\
\hline - Domain I (physical health) & 10.43 & $(1.79)$ & 12.10 & $(1.55)$ & $1.67(1.18 \text { to } 2.16)^{* *}$ & 11.92 & $(2.15)$ & 11.88 & (1.91) & -0.04 & $(-0.44$ to 0.36$)$ \\
\hline - Domain 2 (psychological) & 10.84 & $(1.60)$ & 12.79 & $(1.90)$ & $1.95(1.52 \text { to } 2.38)^{* *}$ & $\mathrm{II} .82$ & (1.99) & 11.97 & (I.7I) & 0.15 & $(-0.22$ to 0.52$)$ \\
\hline - Domain 3 (social relationships) & 12.50 & $(2.22)$ & 14.03 & $(1.95)$ & $1.53(0.94 \text { to } 2.12)^{* *}$ & 12.11 & $(2.25)$ & 12.00 & (l.85) & -0.11 & $(-0.57$ to 0.36$)$ \\
\hline - Domain 4 (environment) & 10.74 & $(2.31)$ & 12.89 & $(1.89)$ & $2.15(1.50 \text { to } 2.80)^{* *}$ & 11.13 & $(2.17)$ & 11.35 & $(2.08)$ & 0.21 & $(-0.12$ to 0.55$)$ \\
\hline
\end{tabular}

$* P<0.05$ (2-sided paired $t$-test); $* * P<0.01$.

HDRS, Hamilton Depression Rating Scale (Hamilton, 1960).

BDQ, Brief Disability Questionnaire (Von Korff et al, 1996).

WHOQOL Bref, WHO Quality of Life Assessment (World Health Organization, 1998).

industrialised countries) (Greenberg, 1993; Kind \& Sorensen, 1993). Although selfreported estimates of specific care-giving activities such as 'help around the home' may not be totally reliable (typically, over-estimation of opportunity cost), use of clearly specified activities and minimal wage rates for a house servant nevertheless help to demonstrate the economic impacts of common psychiatric disorders on the productive opportunity of individuals and families alike.

\section{Strengths and limitations of the study}

An important feature of the chosen study design was that it enabled the prevalence of common mental disorders in the sampled catchment areas to be estimated. This study reinforces the findings of earlier epidemiological studies in each site, that common mental disorders are indeed common, particularly among women (an estimated $12-18 \%$ of the adult populations of the Bangalore catchment areas, and 28-39\% in the Rawalpindi site). Although there are notable differences in the diagnostic profiles of the two sites (high rates of moderate and severe depressive episodes in the Rawalpindi site, and a high prevalence of dysthymia in the Bangalore site), which could be because we used different schedules, the focus of this study was on analysis of health care-seeking patterns within rather than between sites, and our results in fact closely reflect those reported locally in other studies (Ustün \& Sartorius, 1995; Mumford et al, 1997). The observational study design also enabled the healthseeking behaviour of whole catchment populations to be assessed, which demonstrated the economic consequences associated with unmet need at the level of individuals, families and local health services. For example, it was found that only just over half of the sampled populations in the Bangalore site had contacted services at all, and an even smaller proportion were in contact with government primary health care workers.

The high proportion of subjects who did not access government primary health care services in the two localities where mental health care had been integrated confounded the assessment of the relative cost-effectiveness of the programme at the catchment area level (only about half the subjects encountered PHC-based intervention). To sort out this question requires an experimental study design involving the comparison of attenders only at primary care centres, with and without the integrated care model. Comparison between those who did and did not access government primary and secondary services in the integrated care localities, however, showed no statistically significant advantages in clinical or economic outcomes for 
Table 6 Summary of changes in cost' and outcome

\begin{tabular}{|c|c|c|c|c|c|c|c|c|}
\hline \multirow[t]{2}{*}{ Change score } & \multicolumn{2}{|c|}{ All subjects } & \multicolumn{2}{|c|}{ Users $^{2}$} & \multicolumn{2}{|c|}{ Non-users ${ }^{2}$} & \multicolumn{2}{|c|}{ Difference (users v. non-users) } \\
\hline & Mean change & s.d. & Mean change & s.d. & Mean change & s.d. & Mean & $(95 \% \mathrm{Cl})$ \\
\hline Jigani (standard care) & \multicolumn{2}{|c|}{$(n=60)$} & \multicolumn{2}{|c|}{$(n=24)$} & \multicolumn{2}{|c|}{$(n=36)$} & & \\
\hline Service costs & $-R|3|$ & 501 & $+\mathrm{R} 78$ & 347 & $-\mathrm{R} 27 \mathrm{I}$ & 542 & R 348 & $(-598$ to -98$)$ \\
\hline Family costs & $-\mathrm{R} 342$ & 652 & $-\mathrm{R} 407$ & 710 & $-\mathrm{R} 245$ & 553 & $R 162$ & $(-505$ to 182$)$ \\
\hline Depression score (HDRS) & -6.83 & 7.86 & -9.79 & 8.05 & -4.86 & 7.18 & 4.93 & (0.95 to 8.91$)$ \\
\hline Disability (BDQ) & -4.13 & 5.16 & -4.17 & 5.60 & -4.11 & 4.93 & 0.06 & $(-2.80$ to 2.69$)$ \\
\hline Sakalwara (integrated care) & \multicolumn{2}{|c|}{$(n=60)$} & \multicolumn{2}{|c|}{$(n=31)$} & \multicolumn{2}{|c|}{$(n=29)$} & & \\
\hline Service costs & $+R 169$ & 1230 & $+R 366$ & 1324 & $-R 15$ & 1126 & R 38I & $(-1015$ to 253$)$ \\
\hline Family costs & $-R 422$ & 685 & $-R 392$ & 705 & $-R 450$ & 678 & R 58 & ( -415 to 299$)$ \\
\hline Depression score (HDRS) & -5.10 & 6.48 & -5.66 & 7.47 & -4.58 & 5.47 & 1.07 & $(-2.29$ to 4.44$)$ \\
\hline Disability (BDQ) & -5.35 & 5.27 & -6.10 & 4.90 & -4.65 & 5.59 & 1.46 & $(-1.27$ to 4.18$)$ \\
\hline Lehtrar (standard care) & \multicolumn{2}{|c|}{$(n=67)$} & \multicolumn{2}{|c|}{$(n=59)$} & \multicolumn{2}{|c|}{$(n=8)$} & & \\
\hline Service costs & $+\mathrm{R} 48$ & 996 & $+\mathrm{R} 70$ & 1060 & $-\mathrm{R} I \mathrm{II}$ & 132 & $R|8|$ & $(-935$ to 573$)$ \\
\hline Family costs & $-R 634$ & 2294 & $-R 626$ & 2394 & $-R 689$ & 1524 & $\mathrm{R} 62$ & (-1809 to 1684$)$ \\
\hline Depression score (HDRS) & -8.64 & 6.34 & -8.42 & 6.35 & -10.25 & 6.41 & 1.83 & $(-6.61$ to 2.96$)$ \\
\hline Disability (BDQ) & -4.75 & 5.90 & -4.73 & 5.99 & -4.88 & 5.54 & 0.15 & $(-4.62$ to 4.32$)$ \\
\hline Taxila (integrated care) & \multicolumn{2}{|c|}{$(n=63)$} & \multicolumn{2}{|c|}{$(n=20)$} & \multicolumn{2}{|c|}{$(n=43)$} & & \\
\hline Service costs & $+R 370$ & 1984 & $+\mathrm{R} 666$ & 2300 & $-R 299$ & 567 & R 965 & $(-2040$ to 108$)$ \\
\hline Family costs & $+R \quad 1297$ & 1981 & +R 1293 & 2046 & $+R 1304$ & 1889 & R II & $(-1074$ to 1096$)$ \\
\hline Depression score (HDRS) & -0.51 & 5.21 & -0.81 & 5.73 & +0.15 & 3.90 & 0.96 & $(-1.87$ to 3.79$)$ \\
\hline Disability (BDQ) & +0.30 & 2.69 & +0.56 & 2.72 & -0.25 & 2.59 & 0.81 & $(-2.26$ to 0.64$)$ \\
\hline
\end{tabular}

I. In rupees, $\mathrm{R}$ : see Table 4.

2. Users defined as all subjects who had at least one contact with government primary or secondary care services; non-users had no contact with these services.

HDRS, Hamilton Depression Rating Scale (Hamilton, 1960)

BDQ, Brief Disability Questionnaire (Von Korf et al, 1996).

WHOQOL, WHO Quality of Life Assessment (World Health Organization, 1998).

the former subgroup. In particular, the recent introduction of mental health training and support in the main PHC centre in Taxila does not yet appear to have benefited those of the mentally ill population of that area who were in the sample (a plausible reason for this is that there was a strong preference for, and consequent reliance on, private care providers in this population).

A striking finding of the study is the significant improvement in the outcome domains of depression, disability and quality of life for both standard care localities. These results may represent a regression to the mean, or be partly explained by spontaneous remission or improvement (particularly in the Rawalpindi site, where there was a significant proportion of cases with acute depression), but also suggest that interviewing individuals about their mental health state, and advising them to seek care locally, may itself act as an intervention.

\section{Future policy priorities and research needs}

Since governments of low-income countries are fundamentally constrained by lack of resources, constructive ways of harnessing existing local resources must be given consideration, not only in terms of integrating mental health care into the primary care system but also in terms of engaging other professionals and leaders. In many cases the first 'port of call' for an individual with mental disorder (or a member of their household) is the traditional or general practitioner. Simple mental health training for these local private providers might represent an effective means of improving the detection, referral and management of common mental disorders. Of particular relevance in this respect is the currently widespread prescription by local private practitioners of medications for these disorders, the cost of which is invariably met by the patient or family. Training in the detection and treatability of common mental disorders needs to be accompanied by the availability of suitable drugs (and simple psychosocial interventions). Although the high acquisition cost of the newer antidepressants is an obvious constraint, conventional tricyclics are very cheap and equally effective (if not quite as well tolerated). And yet many of the pharmacies visited in the present study do not stock or cannot get such medication. The establishment and implementation of an essential drug list for mental disorders is likely to represent a further policy consideration in many low-income countries.

There remains a chronic shortage of economic data to support discussions on mental health policy or resource allocation at a national or international level. There is consequently a need to undertake further studies that not only address the relative cost-effectiveness of alternative interventions of strategies (using a prospective, experimental study design where possible), but also broaden our understanding of the interrelationship between psychiatric morbidity and disability on the one hand, and access to, and uptake of, services on the other. Indeed, interventions for common mental disorders need to be carefully planned in accordance with the prevailing types of health-seeking behaviour of the local population(s), as well as other demographic, cultural and socio-economic factors, since these factors are likely to contribute significantly to their overall effectiveness and cost-effectiveness. 


\section{ACKNOWLEDGEMENTS}

We acknowledge and thank the staff of the Institute of Psychiatry, Rawalpindi and the National Institute of Mental Health and Neurosciences, Bangalore: in particular, the field workers in each centre Dr Muhammed Naeem Khan and Zafar labal (Rawalpindi); Dr Anita Vasudevan and Chetan Pillai (Bangalore). Dr Catriona Waddington (Institute for Health Sector Development, London) provided additional health economics advice.

\section{REFERENCES}

Chisholm, D., Knapp, M. R. J., Knudsen, H. C., et al (2000) The Client Socio-Demographic and Service Receipt Inventory: development of an instrument for international research. EPSILON study 5. British journal of Psychiatry, 177 (suppl. 39), in press.

Greenberg, P. E. (1993) The economic burden of depression in 1990. Journal of Clinical Psychiatry, 54 $405-418$

Gulbinat, W., Manderscheid, R., Beigel, A., et al (1996) A multinational strategy on mental health policy and care. A WHO collaborative initiative and consultative program. In M. Moscarelli, A. Rupp \& N Sartorius (eds). Handbook of Mental Health Economics and Health Policy, Volume I, Schizophrenia. Chichester: John Wiley \& Sons.

Hamilton, M. (1960) A rating scale for depression. Journa of Neurology, Neurosurgery and Psychiatry, 23, 56-62.

Harding, T. W., De Arango, N., Baltazar, J., et al (1980) Mental disorders in primary health care: a study of their frequency and diagnosis in four developing countries. Psychological Medicine, 10 23|-24|

Jenkins, R. (1997) Nations for Mental Health. Social Psychiatry and Psychiatric Epidemiology, 32, 309-31I.

Kind, P. \& Sorensen, J. (1993) The costs of depression. International Clinical Psychopharmacology, $\mathbf{7}$, 191-195.

Mumford, D., Nazir, M., Jilani, F., et al (1996) Stress and psychiatric disorder in the Hindu Kush: a community survey of mountain villages. British Journal of Psychiatry, 168, 299-307.

_, Saeed, K., Ahmad, I., et al (1997) Stress and psychiatric disorder in rural Punjab: a community survey. British Journal of Psychiatry, 170, 473-478.

Murray, C. J. L. \& Lopez, A. D. (1996) The Global Burden of Diseases: A Comprehensive Assessment of Mortality and Disability from Diseases, Injuries and Risk Factors in 1990 and Projected to 2020. Boston: Harvard School of Public Health, WHO and World Bank.

Patel, V., Pereira, J., Couinho, L., et al (1998) Poverty psychological disorder and disability in primary care

\section{CLINICAL IMPLICATIONS}

- Economic analysis of mental health care programmes in low-income countries is technically feasible and can usefully inform policy and service development.

- The health care and household costs associated with unmet mental health need are considerable.

Following advice to seek local treatment, there were significant improvements in depression and disability ratings in three of the four study localities.

\section{STUDY LIMITATIONS}

The design and scale of this demonstration project precluded the conduct of a controlled, long-term evaluation of changes in costs and outcomes between study areas.

- The low proportion of cases using government primary health care services confounded assessment of the cost-effectiveness of integrating mental health into primary care.

Overlapping categories of informal care-giving imply a potential over-estimation of these costs.

DANIEL CHISHOLM, MSc, Centre for the Economics of Mental Health, Institute of Psychiatry, King's College London; SARAH JAMES, MA, Centre for Development Studies, Swansea (formerly Institute for Health Sector Development, London); K. SEKAR, PhD, K. KISHORE KUMAR, MBBS, R. SRINIVASA MURTHY, MRCPsych, National Institute of Mental Health and Neurosciences, Bangalore, India; KHALID SAEED, FCPS, MALIK MUBBASHAR, FRCPsych, Institute of Psychiatry, Rawalpindi, Pakistan

Correspondence: Daniel Chisholm, Senior Lecturer, Centre for the Economics of Mental Health, Institute of Psychiatry, 7 Windsor Walk, Denmark Hill, London SE5 8BB

(First received 24 May 1999, final revision 22 October 1999, accepted 26 October 1999)

attenders in Goa, India. British Journal of Psychiatry, I72, 533-536.

Shah, A. \& Jenkins, R. (1999) Mental health economic studies from developing countries reviewed in the context of those from developed countries. Acta Psychiatrica Scandinavica, 100, $1-18$

Ustün, T. B. \& Sartorius, N. (eds) (1995) Mental Illness in General Health Care: An International Study. Chichester: John Wiley \& Sons.

Von Korff, M., Ustün, T., Ormel, J., et al (1996) Selfreport disability in an international primary care study of psychological illness. Journal of Clinical Epidemiology, 49 297-303.

World Health Organization (1992a) The ICD-10 Classification of Mental and Behavioural Disorders: Clinical Descriptions and Diagnostic Guidelines. Geneva: WHO.

_ (1992b) Schedules for Clinical Assessment in Neuropsychiatry. Geneva: WHO.

_ Quality of Life Group (1998) Development of the World Health Organisation WHOQOL-Bref Quality of Life assessment. Psychological Medicine, 28, $55 \mathrm{I}-558$. 